\title{
(In)Satisfação dos Valores Laborais e Estresse: Análise de um Modelo Moderacional
}

\author{
Margareth Ribeiro M. S. Silva \\ Faculdade Estácio de Sá de Goiás \\ Helenides Mendonça ${ }^{1}$ \\ Pontifícia Universidade Católica de Goiás
}

\begin{abstract}
RESUMO - O presente estudo objetivou testar um modelo empírico que investiga o poder moderacional da idade e do nível hierárquico sobre a relação entre a (in)satisfação dos valores do trabalho e o estresse psíquico. Para tal, aplicou-se a 220 trabalhadores uma adaptação da Escala de Valores Relativos ao Trabalho e o Questionário de Saúde Geral de Goldberg dimensão do estresse psíquico. A análise de regressão múltipla apontou relação positiva entre estresse psíquico e a insatisfação do valor realização. Já a relação entre insatisfação do valor prestígio e estresse, moderada pela idade, foi negativa, ou seja, entre os mais jovens, a satisfação da busca por exercer autoridade, obter sucesso profissional e poder de influência no trabalho coincidiu com maior propensão ao estresse. Na discussão são consideradas as contribuições e limitações do presente estudo.
\end{abstract}

Palavras-chave: valores laborais, estresse psíquico, prioridades axiológicas relativas ao trabalho

\section{(Dis)Satisfaction of Working Values and Stress: Analysis of a Moderational Model}

\begin{abstract}
The present study aimed to test an empirical model that investigates the moderating effect of age and hierarchical level on the relationship between dissatisfaction with work values and psychological stress. Two instruments were applied to a sample of 220 workers: The Work Values Scale and the psychological stress dimension of the General Health Questionnaire of Goldberg. Multiple regression analysis revealed that psychological stress was positively correlated to dissatisfaction with value realization, whereas the moderation of the age variable showed that, for younger people, the relationship between stress and dissatisfaction with the prestige value was negative. Therefore, the striving of younger people to gain authority, to achieve professional success and power of influence at work make them more prone to stress. In the discussion we take the limits and contributions of this study into consideration.
\end{abstract}

Keywords: work values, psychological stress, axiological priorities relating to work

Os valores, considerados neste estudo como crenças e construtos motivacionais, influenciam o comportamento das pessoas e constituem aspecto central da cultura organizacional. Tornam-se fatores significativos para a compreensão do estresse no trabalho, pois se apresentam como parte importante da experiência pessoal e substrato da vida em grupo e nas organizações.

Desde a primeira revolução industrial, o mundo do trabalho tem sido alterado em sua dinâmica e configuração (Proni, 2006). As alterações relacionadas aos capitalismos financeiro e informacional, cada vez mais incrementadas pela crescente busca por lucro e produtividade, repercutem no ambiente profissional, causando elevadas proporções de desgaste físico e emocional para o trabalhador (Maslach \& Leiter, 1997/1999).

O estresse no trabalho, indicado como um dos fatores de risco para o adoecimento dos trabalhadores (Filgueiras \& Hippert, 2002), tem se tornado um problema econômico e social, com pesados gastos para a saúde pública. Em âmbito mundial, cerca de $30 \%$ dos trabalhadores têm sintomas de depressão, estresse e transtornos de ansiedade (Lobo, 2003).

1 Endereço para correspondência: Rua SB 14, Qd. 19, Lt. 08, Portal do Sol I, Goiânia, Goiás, GO. CEP. 74.884-600.Email: helenides@gmail.com
No Brasil, a doença mental representa a terceira causa de concessão de benefícios previdenciários, como auxílio-doença, afastamento do trabalho por mais de 15 dias e aposentadorias por invalidez (Brasil, 2001; Jacques, 2003).

No ambiente laboral, "os estímulos estressores podem ser provenientes das condições de trabalho, na medida em que as características da tarefa ou as condições físicas, contratuais ou sociais em que se realiza são inadequadas para a pessoa que as executa" (Blanch, 1996, p. 100). Entre as condições laborais estressantes, destacam-se tarefas com prazos muito curtos para execução, ambiguidade de prioridades, nível de autoridade e autonomia, incerteza quanto ao futuro e convívio com colegas insatisfeitos (Lazarus \& Lazarus, 1994).

Outras variáveis que têm sido relacionada ao estresse de trabalhadores são as prioridades axiológicas. Para Locke e Taylor (1991), os valores exercem influência preponderante sobre o estresse, funcionam como pano de fundo para os diversos fatores que permeiam a vivência laboral, vez que são inerentes à identidade do trabalhador e das organizações.

Nas últimas décadas, estudos sobre valores têm sido desenvolvidos por vários pesquisadores (Borges, 2005; Hofstede, 1980; Rokeach, 1973; Ros, Schwartz, \& Surkiss, 1999; Schwartz, 1992), resultando em diferentes modelos teóricos. 
No presente estudo foi adotada a abordagem proposta por Ros et al. (1999). Embora ainda careça de maiores investigações para verificar se a estrutura se mantém em diferentes culturas, essa abordagem possui grande suporte empírico e se mostrou pertinente para a amostra brasileira, conforme confirmado por Porto e Tamayo (2003).

De acordo com o modelo de Ros et al. (1999), os valores laborais se configuram em quatro tipos, a saber: realização no trabalho, relações sociais, prestígio e estabilidade. O modelo desenvolvido pelos autores considera a prioridade atribuída aos valores laborais, mas não abarca a (im)possibilidade de satisfação dos valores e implicações daí decorrentes, o que este estudo procura contemplar. Nesse sentido, são aqui consideradas as relações entre estresse e valores, especialmente aqueles relacionados ao trabalho ou laborais.

\section{Valores e Estresse Psíquico}

A relação entre valores e estresse no trabalho tem sido considerada em estudos específicos sobre os valores, ou referentes a outras variáveis organizacionais, como a cultura e as normas, ou a variáveis individuais, como o coping. Prevalecem investigações concernentes aos valores gerais e não aos valores específicos do trabalho.

Ao considerar a influência que os valores exercem sobre o estresse, Locke e Taylor (1991) propuseram uma estrutura constituída de cinco valores do trabalho e postularam que cada valor está acompanhado de estressores potenciais, relacionados à não satisfação das metas motivacionais. Para Peterson e Wilson (2002), os valores predominantes na organização e as normas daí decorrentes, que não se referem ao elemento humano, apresentam capacidade potencial de gerar conflito, sobrecarga e ambiguidade de papéis, daí decorrendo problemas de saúde, como maiores índices de ansiedade, depressão e doenças psicossomáticas.

Também Cooper e Cartwright (1994, p. 116) identificaram que "a incongruência de valores entre indivíduo e organização, associada à falta de participação na tomada de decisões e comunicação precária, constituem fonte de estresse".

Siu, Spector, Cooper e Lu (2005) observaram que os valores do trabalho exerciam moderação parcial sobre a relação entre estressores e satisfação, o que pode ter sido influenciado pelas condições sociais vividas pelos trabalhadores, por ocasião da coleta de dados.

De acordo com Jex e Bliese (1999), uma discrepância considerável entre os valores individuais e os priorizados pela organização pode levar a efeitos negativos de estresse, o que corrobora os pressupostos estabelecidos por Peiró (1993) e a afirmação de Tamayo (2001) de que a discrepância entre desejos e percepções produz impacto negativo sobre o bem-estar físico e psicológico do empregado.

No Brasil, considerando a relação entre a priorização dos valores pessoais e o adoecer psíquico, Tamayo (2001), em pesquisa com empregados públicos brasilienses, verificou a ocorrência de maior vulnerabilidade ao estresse ocupacional entre os participantes que priorizavam valores gerais referentes à autopromoção, ao hedonismo e à realização. Em estudo ulterior, com odontólogos e operadores de tráfego aéreo, Tamayo (2002) constatou que três tipos motivacionais de valores - tradição, poder e estimulação - prediziam a exaustão emocional. Esses resultados corroboram parcialmente os anteriores, ao demonstrarem que os tipos motivacionais de valores ligados à autopromoção, como o poder, e a abertura à mudança, como a estimulação, estão relacionados à exaustão emocional. Em ambos estudos, Tamayo investigou os valores pessoais e não os valores relativos ao trabalho.

Em pesquisa com estudantes universitários israelenses, Roccas, Sagiv, Schwartz e Knafo (2002, p. 798) concluíram que os "valores podem influenciar mais fortemente atitudes e comportamentos que estão sob controle cognitivo e volitivo, enquanto traços de personalidade podem afetar mais fortemente tendências e comportamentos subjetivos que estão sujeitos a pouco controle cognitivo". Os autores não descartam a possibilidade de influência dos valores sobre a díade saúde-doença, mas concluem que exercem menor influência sobre o adoecer que os traços de personalidade, haja vista o fato de que o adoecer mental não é um comportamento volitivo.

A posição de Roccas et al. (2002) se contrapõe aos resultados apresentados por Tamayo (2001, 2002), demonstrando a necessidade de desenvolver estudos que possibilitem elucidar melhor a relação entre valores e estresse.

Resultado também contrário à existência da relação entre valores e estresse foi identificado na única pesquisa encontrada na literatura que versa sobre os valores laborais, considerados no presente estudo. Ao desenvolver pesquisa com 237 funcionários de uma instituição bancária, Paschoal (2003) identificou que os valores relativos ao trabalho, contrariamente à interferência família-trabalho, não estavam diretamente relacionados ao aparecimento de estresse ocupacional. Para a autora, a ausência dessa correlação pode ter decorrido da inadequação do instrumento utilizado apenas para quantificar o estresse ocupacional, não considerando outras manifestações de saúde-doença mental.

Uma hipótese explicativa para esse resultado, não considerada pela autora, é a de que o estudo abordou somente as priorizações dos valores, e não a impossibilidade de satisfazê-los no contexto organizacional. A discrepância entre a prioridade atribuída aos valores relativos ao trabalho e a efetiva satisfação dos mesmos pode impactar significativamente no estresse.

Não foram identificados estudos versando sobre valores e outras características culturais da organização ou mesmo situações organizacionais específicas, tais como oportunidades de ascensão profissional na empresa.

Assim, depreende-se que, apesar das controvérsias, pode haver relação entre a insatisfação axiológica e o estresse. Por isso, essa hipótese foi adotada no presente estudo. Os achados, embora controversos, não são definitivos, porquanto as variáveis citadas constituem construtos complexos, multideterminados, que podem estabelecer interface com diversos outros fatores. Afinal, as prioridades axiológicas mudam nas diversas fases da vida, em razão da idade, de expectativas sociais, oportunidades e nível de realização, educação, dentre outros fatores que afetam as circunstâncias vitais, como temperamentos, habilidades, ambiente cultural e sistema político (Schwartz, 2005b).

Como os valores são um construto transituacional e a insatisfação axiológica no trabalho algo de que os trabalhadores 
talvez não se apercebam em seu cotidiano, no presente estudo não se considerou o estresse ocupacional e sim as manifestações psíquicas do estresse, que podem ser percebidas também em diversos outros papéis desempenhados pelo indivíduo, e não somente no contexto do trabalho.

\section{Método}

Neste estudo, objetivou-se investigar a relação existente entre a (in)satisfação dos valores do trabalho e o estresse psíquico de trabalhadores. Para isso, buscou-se identificar se: a) a impossibilidade de satisfação das prioridades axiológicas referentes ao trabalho, na organização, está relacionada ao estresse psíquico dos participantes; b) a relação entre a impossibilidade de satisfação axiológica laboral e o estresse é moderada pela idade e pelo nível hierárquico dos participantes.

Propõe-se que a relação entre a insatisfação dos valores e o estresse é moderada pela idade e pelo nível hierárquico. O modelo moderacional adotado (Figura 1), proposto por Ribeiro (2006), considera que a insatisfação das prioridades axiológicas relativas ao trabalho $(\mathrm{A}=$ variável independente $)$ influencia para mais ou para menos o estresse psíquico no trabalho ( $\mathrm{B}=$ variável dependente). Essa relação é também influenciada por idade e nível hierárquico dos trabalhadores $(\mathrm{C}=$ variável moderadora $)$.

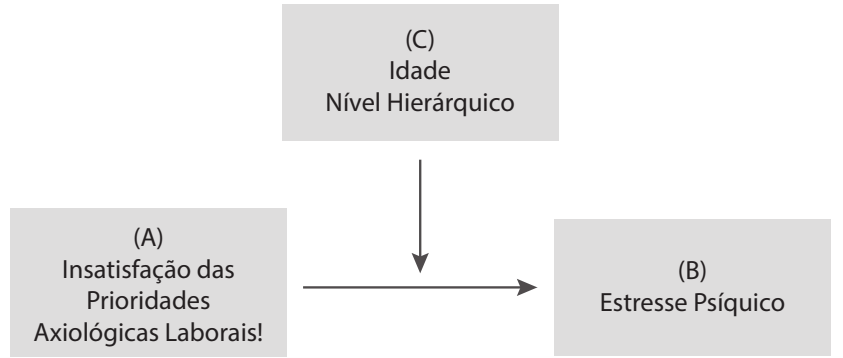

Figura 1. Diagrama do modelo de investigação adotado no estudo. Fonte: Ribeiro (2006).

Com base nas contribuições teóricas e nos objetivos propostos, emergiram três hipóteses de investigação. Autores como Cooper e Cartwright (1994) e Tamayo (2001) evidenciaram a possibilidade de comprometimento da saúde mental de trabalhadores quando há incongruência entre valores priorizados pelos indivíduos e pelas organizações em que trabalham. A concepção de incongruência considerada por esses pesquisadores aproxima-se da concepção adotada no presente estudo, pois a insatisfação percebida pelo trabalhador reflete oportunidades oferecidas pela organização. Todavia, não são consideradas como sinônimo porque neste estudo os valores organizacionais não foram identificados separadamente dos valores pessoais, para posterior comparação. Assim, esperava-se que a insatisfação das prioridades axiológicas estivesse positivamente relacionada com o estresse psíquico, manifesto por intermédio de altos escores nesse fator do Questionário de Saúde Geral (QSG) (hipótese 1).

A literatura pertinente ao tema apresenta estudos que relatam a interferência da idade sobre os valores (Johnson,
2001; Schwartz, 2005a), até porque esta "geralmente implica outras variáveis, tais como nível de escolaridade, experiência profissional, etc.” (Tamayo, 1988, p. 94). Então, esperava-se que a relação entre discrepância axiológica laboral e estresse fosse moderada pela idade (hipótese 2).

Também foram identificados relatos de pesquisas sobre os valores gerais e inserção do indivíduo na estrutura social de classe (Borges, 1996), interferência da classe social sobre as orientações de valores individuais (Kohn \& Schooler, 1982) e variações dos atributos dos significados do trabalho em função do nível hierárquico (Borges, 1996). Todavia, não foram encontrados estudos sobre a relação específica entre nível hierárquico e valores laborais. Considerando que "as organizações brasileiras apresentam uma distância de poder tão grande que parecem lembrar a distribuição de renda nacional e o passado escravocrata" (Motta \& Caldas, 1997, p. 31), esperava-se que diferenças no nível hierárquico interferissem na relação entre valores e estresse, bem como que a relação entre discrepância axiológica laboral e estresse fosse moderada pelo nível hierárquico do trabalhador (hipótese 3).

\section{Caracterização da empresa}

Esta pesquisa foi realizada em empresa de economia mista, que possui regionais distribuídas em todo o estado de Goiás e no Distrito Federal. Detém o monopólio em seu ramo de atuação e ocupa o primeiro lugar entre as concessionárias da Região Centro-Oeste em faturamento, número de consumidores e tempo de atendimento, e o sexto lugar no ranking nacional, tendo recebido, em 2005, importante prêmio por seu desempenho no setor.

Desde 2003, adotou medidas administrativas objetivando recuperação financeira, as quais contribuíram para que seu balanço financeiro se tornasse positivo. Possui cinco níveis em sua estrutura organizacional e a escolha dos gestores tem como critérios a experiência e o notório conhecimento $(50 \%)$, além de indicação política (50\%). As mudanças gerenciais acompanham mudanças no governo estadual que, normalmente, ocasionam alterações de gestão, orientações e organização de processos de trabalho.

As pressões decorrentes do contexto de trabalho estão sempre presentes, especialmente nas áreas operacionais, e advêm de consumidores e órgãos fiscalizadores estaduais e federais, além do Ministério Público e Tribunal de Contas.

Há risco de vida em algumas funções operacionais já tendo ocorrido acidentes com vítima fatal. As relações com o sindicato dos empregados são "predominantemente saudáveis", segundo o Gerente de Recursos Humanos da empresa. Embora os salários sejam competitivos e estejam acima da média do mercado, os contratados mais recentes reclamam da remuneração recebida.

Os empregados são contratados de acordo com o regime da Consolidação das Leis Trabalhistas, mediante aprovação em concurso público. Após a contratação, realizam estágio probatório de três meses, ao final do qual podem ser efetivados ou demitidos. A inclusão de novos contratados é feita mediante treinamento introdutório. Existe competitividade entre novos e antigos empregados. De acordo com o Ge- 
rente de Recursos Humanos da empresa, informalmente, a Área de Recursos Humanos observa nos empregados mais jovens uma "ânsia, uma angústia, uma premência, uma fadiga para progredir depressa, ser chefe depressa, ter aumento salarial depressa, sem considerar a necessidade da experiência e da qualificação". Ainda segundo ele, também tem sido crescente, entre os empregados, a "incidência de episódios de depressão, desarranjo familiar, uso de drogas e adoecimentos".

A empresa foi escolhida para este estudo por ter passado por mudanças administrativas que apontam a necessidade de atenção à saúde psíquica de seus empregados. Também a estabilidade e o longo tempo de serviço de seus empregados (média de 20 anos) sugerem a possibilidade de maior facilidade para identificar satisfação ou insatisfação dos valores laborais.

\section{Participantes}

Participaram do estudo 220 funcionários contratados há mais de um ano, os quais foram selecionados aleatoriamente, entre os 1.557 empregados lotados na sede da empresa, em Goiânia, na época da coleta de dados. A idade média dos participantes foi de 41,8 anos $(d p=11,39)$, a média de tempo de serviço, de 15,46 anos $(d p=11,04)$, a escolaridade predominante foi equivalente ao ensino médio completo $(41,4 \%)$, sendo $82 \%$ participantes do sexo masculino e $17 \%$ gestores.

Segundo a idade, categorizada a partir dos períodos do desenvolvimento adulto, propostos por Levinson e Gooden (citados por Kaplan, Sadock, \& Grebb, 1997), a amostra ficou assim distribuída: 19 a 25 anos, 12\%; 26 a 30 anos, 11\%; 31 a 40 anos, 18\%; 41 a 50 anos, 32\%; e 51 a 65 anos, $27 \%$.

\section{Instrumentos}

\section{Escala de valores relativos ao trabalho (EVT)}

A Escala de valores relativos ao trabalho (EVT), construída e validada por Porto e Tamayo (2003, 2008), é composta por 45 itens, agrupados em quatro fatores, que correspondem aos valores laborais considerados no presente estudo, a saber: realização no trabalho, relações sociais, prestígio e estabilidade. Considerando os objetivos desta pesquisa, foi acrescida uma coluna à EVT, na qual o respondente deveria registrar sua percepção acerca do fato de a organização em que trabalha permitir a satisfação dos seus valores relativos ao trabalho. Essa inclusão permitiu identificar a satisfação e/ou a insatisfação dos valores laborais.

As respostas para cada item são dadas segundo uma escala Likert de cinco posições. O escore final de cada fator indicativo dos valores priorizados e dos valores satisfeitos resulta da soma das respostas correspondentes aos números da escala de cinco pontos, dividida pelo total de itens do fator. A discrepância axiológica é determinada pela diferença entre os escores referentes aos valores priorizados e os escores correspondentes à satisfação dos respectivos valores.

A escala foi submetida à análise semântica com 10 participantes que, após respondê-la, foram questionados sobre as dificuldades encontradas e a compreensão dos itens. Posteriormente, realizou-se um pré-teste da escala em amostra de 178 alunos universitários de Goiânia, com idade média de 30,46 anos $(d p=8,2)$, sendo $59,6 \%$ do sexo feminino, $41 \%$ da amostra desempenhando funções de gestão e tempo médio de serviço equivalente a cinco anos.

Os itens da escala foram submetidos a uma análise fatorial (PAF), com rotação Varimax, utilizando os dados do pré-teste. Posteriormente, os dados da amostra foram também submetidos aos mesmos procedimentos para confirmar a estrutura proposta por Porto e Tamayo (2003) e os resultados do pré-teste indicaram que os fatores se agrupam, conforme proposto pelos autores.

Os resultados apresentados pela amostra considerada para o estudo indicaram alfas menores que os encontrados no pré-teste, o que pode estar relacionado às diferenças entre as características sócio-demográficas das duas amostras. Apesar dos baixos alfas de Cronbach obtidos na amostra considerada para este estudo, foram mantidos todos os itens da escala original, pois esta havia sido previamente validada e publicada (Porto \& Tamayo, 2003).

\section{Questionário de saúde geral (QSG) / Dimensão do estresse psíquico}

O Questionário de Saúde Geral (QSG) foi criado por Goldberg (1972), objetivando obter definições precisas nos diagnósticos para os casos nos quais o limite entre a saúde e a doença eram influenciados pela sociedade e cultura. Traduzido, adaptado e validado no Brasil por Pasquali, Gouveia, Andriola, Miranda e Ramos (1996), destina-se à identificação do estado atual de saúde mental do respondente, no que se refere a sintomas, sentimentos, pensamentos e comportamentos observáveis não-psicóticos. É autoaplicável, composto por 60 itens expressivos de comportamentos, que enfatizam a severidade da ausência de saúde mental, mediante um fator geral e cinco fatores específicos: a) estresse psíquico, com 13 itens; b) desejo de morte, com 8 itens; c) desconfiança quanto ao próprio desempenho, com 17 itens; d) distúrbios do sono, com 6 itens; e) distúrbios psicossomáticos ou problemas de ordem orgânica, com 10 itens. Para os propósitos do presente artigo foram considerados somente os itens referentes ao estresse psíquico. As respostas para cada item são dadas segundo uma escala Likert de quatro pontos e o escore final de cada fator resulta da soma das respostas correspondentes aos números da escala, de tal modo que o comprometimento da saúde mental será maior quanto maiores forem os resultados percentuais demonstrados.

A utilização do QSG no presente estudo se justifica por ser um instrumento auto-aplicável, de rastreamento simples, que permite diagnóstico objetivo. Expressa comportamentos e sentimentos atuais e não traços de personalidade, em população não clínica, possibilitando integração entre questões vinculadas ao trabalhador e às características organizacionais. Permite investigar grande numero de indivíduos simultaneamente, com redução de tempo e de custo, sendo de largo uso em pesquisas no Brasil e em outros países, conforme amplamente relatado por Pasquali et al. (1996). Apresenta índices altos de precisão, especificidade e sensibilidade, sendo que a análise de consistência interna do fator estresse 
psíquico (13 itens) identificada por meio do alfa de Cronbach apresentou coeficiente $\alpha=0,89$

\section{Procedimentos}

Os participantes do estudo foram orientados, coletivamente, sobre o propósito da pesquisa, assinaram o Termo de Consentimento Livre e Esclarecido e responderam individualmente à EVT e ao QSG. As informações sobre as características da organização foram obtidas por meio de entrevista com o representante da Gerência de Recursos Humanos da empresa.

\section{Resultados}

Os dados coletados pela aplicação da EVT e do QSG foram analisados por aglomerado e receberam tratamento estatístico, por meio do pacote estatístico SPSS para Windows, versão 11.0, com o qual foram obtidos os resultados relativos a frequências, médias, desvios-padrão e correlações ( $r$ ) para avaliar a força e o sentido da relação entre as variáveis, análises de variância e coeficientes de fidedignidade das escalas - os alfas de Cronbach -, realizando-se análise de correlação e regressão múltipla.

A análise preliminar dos dados demonstrou que os mesmos atendem aos pressupostos exigidos para a análise de regressão múltipla. Os histogramas com sobreposição da curva normal evidenciaram distribuição das variáveis próxima ao normal, razão pela qual não houve necessidade de transformação dos dados. Os testes de linearidade e homocedasticidade demonstraram relações lineares entre as variáveis do estudo. Em adição, verificou-se ausência de multicolinearidade.

Para identificar se a relação entre insatisfação das prioridades axiológicas relativas a trabalho e estresse psíquico é moderada pela idade e nível hierárquico, realizaram-se análises de regressão múltipla. Os resultados demonstraram que o estresse psíquico foi predito pelo efeito principal da insatisfação das prioridades axiológicas de prestígio e a idade dos trabalhadores. A hipótese 3 foi rejeitada, haja vista não ter havido a moderação do nível hierárquico sobre a relação entre a (in)satisfação axiológica laboral e o estresse psíquico dos participantes.

As variáveis preditoras e a idade foram padronizadas, de modo a apresentar média zero e desvio padrão igual a 1. Para a variável nível hierárquico, foram atribuídos códigos de efeitos ponderados e, a seguir, calculados os termos de interação, multiplicando-se cada preditor pelos moderadores. Foram usados modelos de equações de regressão, como recomendado por Baron e Kenny (1986) e Frazier, Barron e Tix (2004). A equação considera a moderação da idade e do nível hierárquico sobre a relação entre os valores e o estresse psíquico. Os resultados (Tabela 1) demonstraram coeficiente de regressão múltipla significativamente diferente de zero $\left(\mathrm{R}=0,482 ; \mathrm{R}^{2}=\right.$ $0,179 ; F(14,200)=4,323 ; p<0,001)$. Os efeitos principais da idade e do nível hierárquico não foram significativos.

Observou-se efeito isolado da insatisfação do valor realização sobre o estresse psíquico $(\mathrm{B}=0,272$; $\mathrm{SE}=$
Tabela 1. Resultado da regressão linear múltipla aplicada à análise dos fatores preditivos de estresse psíquico.

\begin{tabular}{|c|c|c|c|}
\hline & \multicolumn{3}{|c|}{ Estresse psíquico } \\
\hline & Beta & $t$ & $p<$ \\
\hline \multicolumn{4}{|l|}{$\begin{array}{l}\text { Variáveis sociodemográficas } \\
\text { (moderadoras) }\end{array}$} \\
\hline Idade & $-0,100$ & $-1,424$ & n. s. \\
\hline Nível hierárquico & 0,073 & 0,974 & n. s. \\
\hline \multicolumn{4}{|l|}{$\begin{array}{l}\text { Discrepâncias } \\
\text { (variáveis independentes) }\end{array}$} \\
\hline Realização & 0,463 & 3,572 & 0,001 \\
\hline Relações sociais & $-0,067$ & $-0,663$ & n. s. \\
\hline Prestígio & $-0,123$ & $-1,376$ & n. s. \\
\hline Estabilidade & 0,081 & 0,808 & n. s. \\
\hline \multicolumn{4}{|l|}{ Interações } \\
\hline Idade $\mathrm{x}$ realização & 0,062 & 0,513 & n. s. \\
\hline Idade $\mathrm{x}$ relações sociais & $-0,118$ & $-1,237$ & n. s. \\
\hline Idade $\mathrm{x}$ prestígio & 0,180 & 1,825 & 0,06 \\
\hline Idade $\mathrm{x}$ estabilidade & $-0,031$ & $-0,348$ & n. s. \\
\hline Nível hierárquico x realização & 0,030 & 0,280 & n. s. \\
\hline $\begin{array}{l}\text { Nível hierárquico x relações } \\
\text { sociais }\end{array}$ & $-0,103$ & $-1,076$ & n. s. \\
\hline Nível hierárquico x prestígio & 0,029 & 0,275 & n. s. \\
\hline $\begin{array}{l}\text { Nível hierárquico x } \\
\text { estabilidade }\end{array}$ & 0,094 & 0,979 & n. s. \\
\hline $\begin{array}{l}\text { Coeficiente de } \\
\text { regressão múltipla }\end{array}$ & \multicolumn{3}{|c|}{$R=0,482$} \\
\hline Explicação da variabilidade & \multicolumn{3}{|c|}{$R^{2}=0,23 ; R^{2}$ ajustado $=0,18$} \\
\hline Teste estatístico do modelo & \multicolumn{3}{|c|}{$F(14,200)=4,32 ; p<0,001$} \\
\hline
\end{tabular}

$0,067 ; \beta=0,524 ; t=4,034 ; p<0,001)$, indicando que a insatisfação de busca de prazer e realização profissional, de independência de pensamento e ação no trabalho, mediante autonomia intelectual e da criatividade, pode promover estresse psíquico.

A análise dos parâmetros estimados pelo modelo moderacional evidenciou que o efeito principal da insatisfação do valor prestígio sobre o estresse psíquico não foi significativo. Todavia, esse efeito foi qualificado por interação marginalmente significativa entre insatisfação e idade $(\mathrm{B}=0,081$; $\mathrm{SE}=0,043 ; \mathrm{b}=0,181 ; t=1,881 ; p<0,06)$.

Para interpretar o efeito da moderação foram compostos os simple slopes, que permitem projeção das linhas de regressão, que representam os escores referentes à dimensão do estresse psíquico, preditos pelos escores com um desvio-padrão acima e abaixo da média referente às discrepâncias axiológicas, separadamente para cada uma das variáveis moderadoras - idade e nível hierárquico. Adicionalmente, com base nos erros-padrão e nos intervalos de confiança (IC) para os coeficientes de inclinação das retas de regressão (" $B s$ "), verificou-se se esses coeficientes eram significativamente diferentes de zero (Frazier et al., 2004). 


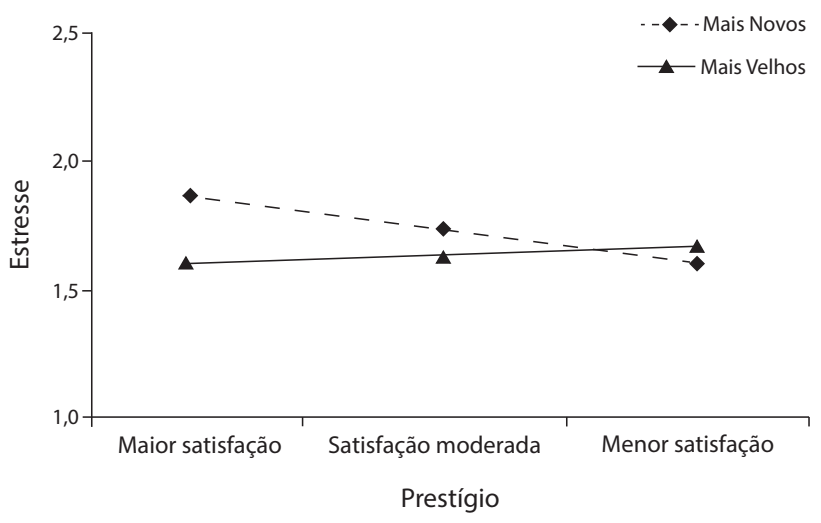

Figura 2. Linhas de regressão representando a relação entre o nível de satisfação do valor prestígio em relação ao estresse psíquico, moderado pela idade.

Essas linhas de regressão (Figura 2) indicam, portanto, que indivíduos mais novos, com maior insatisfação do valor prestígio, experimentam menos estresse, confirmando a hipótese 2. Para os mais velhos, a relação não é significativa, ou seja, a interação é apenas marginalmente significativa.

Esses resultados confirmam a hipótese 1, segundo a qual a insatisfação das prioridades axiológicas estaria positivamente relacionada com o estresse psíquico. Identificou-se que a impossibilidade de satisfazer prioridades referentes ao valor realização está relacionada com o estresse, o que não ocorre com os demais valores.

\section{Discussão}

Este estudo teve como objetivo testar um modelo empírico que investiga o poder moderacional da idade e do nível hierárquico sobre a relação entre a (in)satisfação dos valores do trabalho e o estresse psíquico de trabalhadores.

Ao confirmar as relações hipotetizadas de que quanto maior a insatisfação axiológica, maior a possibilidade de manifestações de estresse psíquico, este estudo representa significativa contribuição às pesquisas sobre estresse e saúde mental de trabalhadores, especialmente considerando as controvérsias sobre o tema (Paschoal, 2003; Roccas et al., 2002). Evidencia-se a sutil possibilidade de que os modos como se estruturam as relações do homem com seu trabalho, no contexto organizacional, contribuem para a sua desumanização, haja vista a redução de suas possibilidades de autonomia e criatividade (Codo, Sampaio, \& Hitomi, 1993).

As correlações entre insatisfação das prioridades axiológicas e estresse corroboram o importante papel desempenhado pelo valor realização, pois se refere ao sucesso profissional baseado no êxito do trabalho, da independência e da satisfação de diversas necessidades. Esse valor parece adquirir especial importância para o indivíduo, uma vez que é privilegiado pelos pais no processo de transmissão axiológica, durante a socialização primária (Porto, 2004). Pode-se questionar, ainda, se tal correlação referente à realização e ao prestígio, não reflete uma tendência do regime capitalista de culpar o indivíduo por suas falhas e insucessos.

Esses resultados coincidem com a concepção de Locke e Taylor (1991), segundo a qual, a possibilidade de falhas no trabalho e na carreira, a perda de controle e de prestígio, são fatores potencialmente estressantes e relacionados a categorias de valores pertinentes à realização e aos valores materiais.

A relação entre insatisfação do valor realização e adoecimento psíquico remete ao tema da incongruência básica entre a personalidade do trabalhador e a organização formal (Argyris, 1973). Isso aparece e se agrava à medida que a organização obriga o indivíduo a se submeter a seus procedimentos, rotinas, regras, tornando-o submisso e fazendo-o atuar sob forte controle, com restritas possibilidades de liberdade.

Os objetivos estratégicos das organizações direcionam-se cada vez mais intensamente para altos níveis de exigência em termos de excelência, promovendo elevado custo pelo sucesso obtido e comprometimentos à saúde mental, tal como a doença da idealização, identificada por Aubert (1990/1994). A própria organização estrutura-se e desenvolve processos produtivos que asseguram seus resultados; porém, nem sempre permite a criatividade ou a autonomia de pensamento intelectual.

Indubitavelmente, a organização aqui avaliada dedica-se à busca de maior excelência, em decorrência das pressões que recebe dos consumidores e de órgãos fiscalizadores. Porém, parece haver um descompasso entre os resultados obtidos pela organização e as possibilidades para oportunizar a realização profissional, a autonomia intelectual e a criatividade de seus empregados.

É interessante a ausência de correlação entre a insatisfação dos valores afetos à busca de estabilidade e relações sociais positivas no trabalho e o estresse. Como esses valores apresentaram os maiores índices de satisfação, deve-se considerar a possibilidade de que a qualidade das relações na empresa, bem como a estabilidade assegurada pelo elevado tempo de permanência no emprego e por salários competitivos em relação aos praticados no mercado, estejam contribuindo positivamente para o estresse psíquico dos participantes da pesquisa.

É oportuno lembrar que o suporte social proporciona ao indivíduo sentimentos de estabilidade e controle, conduzem-no a perceber o ambiente de maneira mais positiva e motivam-no a utilizar maiores recursos pessoais para enfrentar o estresse (Almagiá, 2005). A combinação desses fatores pode aumentar sua resistência às enfermidades e provocar efeitos positivos em seu bem-estar emocional.

$\mathrm{O}$ modelo moderacional proposto, concernente às hipóteses 2 e 3, foi confirmado somente para a discrepância referente ao valor prestígio, cuja relação com o estresse é moderada pela idade, de tal modo que, entre os trabalhadores mais jovens, quanto maior a discrepância relativa a esse valor laboral, menor é o índice de estresse psíquico. Expresso de outro modo, quanto menos os jovens realizam metas afetas ao valor prestígio, menores as possibilidades de manifestações sintomáticas referentes ao estresse. Assim, a maior satisfação do valor prestígio está significativamente relacionada com a possibilidade de estresse psíquico entre os mais jovens.

Reportando-se à ideia de que a busca por prestígio poderia ser fortemente influenciada por uma paradoxal forma de vivenciar esse valor, associada aos traços culturais historicamente caracterizados desde o Brasil colônia, parece pertinente deduzir que investimentos individuais para realizar esse valor não ocorram com isenção de algum custo emocional. 
"A variável idade raramente pode ser completamente isolada, implicando geralmente outras variáveis como escolaridade e experiência profissional" (Tamayo, 1988, p. 94). A idade adulta jovem é, por excelência, um momento do desenvolvimento em que ocorrem mudanças significativas, referentes à escolaridade, à inserção no mercado de trabalho, à constituição de nova família, entre outras. Tal condição torna o adulto jovem mais vulnerável ao estresse. A ocorrência de maior estresse entre os mais jovens, decorrente de menor satisfação do valor prestígio, está amplamente apoiada por literatura pertinente ao desenvolvimento humano.

Também no contexto laboral, o maior nível de estresse entre adultos jovens, comparativamente a adultos mais velhos, foi identificado por Fernandes, Di Pace e Passos (2002) em pesquisa com operadores de telemarketing, na qual os autores utilizaram uma forma reduzida do QSG.

No presente estudo, não foi observada moderação do nível hierárquico sobre a relação entre a (in)satisfação axiológica laboral e o estresse psíquico dos participantes. Esse resultado pode estar relacionado com características intrínsecas às funções de nível hierárquico mais elevado, tal como sua transitoriedade. Como a organização se baseia em experiência e notório conhecimento, além de indicação política para designar ocupantes de função gerencial, isso torna a ocupação de tais níveis ainda mais provisória, motivo pelo qual talvez não se apresente como algo capaz de afetar as circunstâncias vitais, como assinalado por Schwartz (2005a).

\section{Considerações Finais}

Considerando as limitações do presente estudo, são apresentadas sugestões para desenvolvimento de novas pesquisas, visando lançar mais luz sobre este relevante tema. Uma investigação oportuna poderia contemplar a relação entre insatisfação do valor estabilidade e estresse de trabalhadores de empresas de diferentes naturezas jurídicas, a exemplo das privadas, nas quais a rotatividade é alta ou o tempo médio de serviço é menor que o constatado na organização do presente estudo.

Outra rica possibilidade de investigação seria considerar amostras com maior número de mulheres, para verificar se algumas prevalências relativas ao gênero se aplicam também em casos de insatisfação axiológica laboral. Para Hofstede (1980), é próprio da cultura brasileira maior distanciamento entre ocupantes de diferentes níveis hierárquicos. Portanto, seria interessante investigar como a correlação se comporta mediante as possibilidades de (in)satisfação do valor relações sociais entre ocupantes do mesmo nível hierárquico ou de grupos hierárquicos diferentes.

Os resultados referentes à moderação da idade sobre a relação entre insatisfação do valor prestígio e estresse psíquico remetem às relações entre valores e ansiedade como um princípio organizador da estrutura de valores. Para Schwartz (2005b, p. 48), a busca de alguns valores "serve para lidar com a ansiedade derivada da incerteza do mundo". Decorre, então, uma questão: a satisfação do valor prestígio é buscada para reduzir a ansiedade referente ao estresse que seria oriundo de outros fatores próprios da idade adulta jovem e à desconfiança quanto ao próprio desempenho? Ou a busca por satisfazer os valores afetos ao valor prestígio promove tais manifestações sintomáticas?

Estudos complementares com os participantes da amostra, cujos resultados demonstraram a existência de sintomas, poderiam contribuir para melhor compreender como os processos de estresse psíquico, de seu enfrentamento e convivência com os processos de trabalho e interações com colegas se caracterizam. Tal investigação, provavelmente, seria beneficiada com o uso de metodologias características da abordagem epidemiológica e/ou qualitativa em pesquisa sobre saúde-doença mental no trabalho (Codo, 2002).

Em decorrência dos resultados obtidos, recomenda-se como agenda de intervenção na organização a adoção de medidas que proporcionem melhor alinhamento entre valores laborais pessoais e valores organizacionais, tais como a revisão dos modelos de gestão atualmente praticados, buscando efetivar um modelo de gestão efetivamente sinérgico e participativo. Esse modelo é o que mais implica vivência respeitosa dos valores, possibilitada por comunicação, sinergia, real compartilhamento de visão estratégica e melhoria de competências individuais (Chanlat, 1995; Toledo \& Regis, 1996).

Levando em consideração a existência de escores sintomáticos entre os integrantes da amostra, recomenda-se o desenvolvimento de ações organizacionais para identificar, criteriosamente, as condições de estresse entre todos os empregados, particularmente entre os mais jovens.

As ações direcionadas à preservação da saúde ocupacional comumente restringem-se ao cumprimento de normas regulamentadoras que não contemplam os fatores psicossociais de risco. Também é de fundamental importância o desenvolvimento de programas coletivos preventivos de estresse, iniciando-se pela inclusão da psicossociologia nas metodologias de avaliação de risco laboral, nos desenhos de cargos e no estabelecimento de políticas de progressão na empresa (Martinez, Albacar, \& Alcázar, 2009).

Devem ser promovidas atividades de orientação e acompanhamento dos indivíduos sintomáticos, bem como outras ações de gerenciamento do estresse, para evitar o aumento da severidade dos casos existentes ou o incremento na quantidade de tais ocorrências. Entre as ações preventivas, sugerem-se:

a) identificação das necessidades axiológicas relativas à realização, como controle sobre as atividades desempenhadas no trabalho, habilidade para lidar com pressões do tempo, maturidade nos relacionamentos no contexto de trabalho, demonstração de competência, valorização e reconhecimento pelo trabalho realizado, objetivando definir ações mais adequadas à promoção da saúde dos empregados;

b) identificação do significado atribuído pelos empregados ao trabalho nessa organização, mediante programas estruturados de sensibilização, com intensa participação dos gestores;

c) desenvolvimento de política de gestão de pessoas dirigida estrategicamente à promoção da saúde mental dos empregados, não segundo concepção fundamentada somente nas recomendações legais do Ministério da Saúde, mas que contemple, também, aspectos subjetivos do processo saúde-doença mental no trabalho. 
Os resultados obtidos e as conclusões apresentadas demonstram a importância e a aplicabilidade do presente estudo para o campo da Psicologia Organizacional e do Trabalho, bem como para subsidiar estratégias de gestão de pessoas.

Esta pesquisa é uma exploração inicial para o desenvolvimento de outras sobre a insatisfação das prioridades axiológicas laborais e sua relação com o estresse, abrangendo aspectos ainda não contemplados em outros estudos sobre o tema.

\section{Referências}

Almagiá, E. B. (2005). Estados afectivos e expresión emocional. In L. Flórez-Alarcón, M. M. Botero, \& B. Moreno-Jiménez (Eds.), Psicología de la salud: temas actuales de investigación en Latinoamérica (pp. 103-114). Bogotá: Uninorte y Alapsa.

Argyris, C. (1973). Personalidade e Organização Rio de Janeiro: Renes.

Aubert, N. (1994). A neurose profissional. In J. F. Chanlat. (Ed.), O indivíduo na organização: dimensões esquecidas v. 2 (pp. 165-171). (A. M. Rodrigues, L. dos S. Gaino, M. T. Gomes, \& O. Torres, Trad.). São Paulo, Atlas/HEG/Cetai. (Trabalho original publicado em 1990)

Baron, R. M., \& Kenny, D. A. (1986). The moderator-mediator variable distinction in social psychological research: Conceptual, strategic and statistical considerations. Journal of Personality and Social Psychology, 51, 1173-1182

Blanch, J. M. (1996). Psicología social del trabajo. In J. L. Álvaro, A. Garrido, \& J. R. Torregrosa (Eds.), Psicologia social aplicada (pp. 85-120), Madrid: McGraw-Hill.

Brasil. Ministério da Saúde do Brasil. (2001). Doenças relacionadas ao trabalho. Manual de procedimentos para os serviços de saúde. Brasília, DF.

Borges, L. O. (1996). A representação social do trabalho. Estudos de Psicologia, 1, 7-25.

Borges, L. O. (2005). Valores de trabalhadores de baixa renda. In A. Tamayo \& J. B. Porto (Eds.), Valores e comportamento nas organizações (pp. 233-250). Petrópolis: Vozes.

Chanlat, F. (1995). Modos de gestão, saúde e segurança no trabalho. In E. Davel \& J. Vasconcelos (Eds.). Recursos humanos e subjetividade (pp. 11-129). Petrópolis: Vozes, 1995. p. 111-129.

Codo, W., Sampaio, J. J. C., \& Hitomi, A. H. (1993). Indivíduo, trabalho e sofrimento - uma abordagem interdisciplinar. Petrópolis, RJ: Vozes.

Codo, W. (2002). Um diagnóstico integrado do trabalho com ênfase em saúde mental. IN M. G. Jacques \& W. Codo (Eds.), Saúde mental \& trabalho - leituras (pp. 173-192). Petrópolis: Vozes.

Cooper, C. L., \& Cartwright, S. (1994). Healthy mind: healthy organizations - a proactive approach to occupational stress. Human Relations, 47, 455-471.

Fernandes, S. R. P, Di Pace, D. M. T., \& Passos, M. F. D. (2002). Organização e condições de trabalho em telemarketing: repercussões na saúde psíquica dos trabalhadores. In M. G. Jacques \& W. Codo (Eds.), Saúde mental \& trabalho:leituras (pp. 247-270). Petrópolis, RJ: Vozes.

Filgueiras, J. C., \& Hippert, M. I. (2002). Estresse: possibilidades e limites. In M. G. Jacques \& W. Codo (Eds.), Saúde mental \& trabalho-leituras (pp. 112-129). Petrópolis, RJ: Vozes.
Frazier, P. A., Barron, K. E., \& Tix, A. P. (2004). Testing moderator and mediator effects in counseling psychology. Journal of Counseling Psychology, 51, 115-134.

Goldberg, D. P. (1972). The detection of psychiatric illness by questionnaire. Londres: Oxford University Press.

Hofstede, G. (1980). Culture's consequences: international differences in work related values. Newbury Park: Sage Publications.

Jacques, M. G. C. (2003). Abordagens teórico-metodológicas em saúde/doença mental e trabalho. Psicologia \& Sociedade, 15, 97-116.

Jex, S. M., \& Bliese, P. D. (1999). Efficacy beliefs as a moderator of the effects of work-related stressors: A multi-level study. Journal of Applied Psychology, 84, 349-36.

Johnson, M. K. (2001). Job values in the young adult transition: change and stability with age. Social Psychology Quarterly, 64, 297-317.

Kaplan, H., Sadock, B., \& Grebb, J. A. (1997). Compêndio de psiquiatria clínica. Porto Alegre: Artes Médicas.

Kohn, M. L., \& Schooler, C. (1982). Job conditions and personality: A longitudinal assessment of their reciprocal effects. American Journal of Sociology, 87(6), 1257-1286.

Lazarus, R. S., \& Lazarus, S. B. N. (1994). Passion and reason: making sense of our emotions. New York: Oxford University Press.

Lobo, F. (2003). Vida e morte no trabalho. Carta Capital, 10, 12-15.

Locke, E. A., \& Taylor, M. S. (1991). Stress, coping, and the meaning of work. In A. Monat, \& S. R. Lazarus (Eds.), Stress and coping: an anthology (pp. 140-157). New York: Columbia University Press.

Martinez, V. S., Albacar, A. G., \& Alcázar, I. G. (2009). Experiencias en intervención psicosocial - más allá de la evaluación del riesgo. Madrid: Instituto Nacional de Seguridad e Higiene en el Trabajo.

Maslach, C., \& Leiter, P. M. (1999). Trabalho: fonte de prazer ou desgaste? Guia para vencer o estresse na empresa (M. S. Martins, Trad.). Campinas, SP: Papirus (Trabalho original publicado em 1997)

Motta, F. C. P., \& Caldas, M. P. (1997). Cultura organizacional e cultura brasileira. São Paulo: Atlas.

Paschoal, T. (2003). Relação dos valores do trabalho e da interferência família-trabalho como estresse ocupacional. Dissertação de mestrado, Universidade de Brasília, Brasília, DF.

Pasquali, L., Gouveia, V. V., Andriola, W. B., Miranda, F. J., \& Ramos, A. L. M. (1996). Questionário de saúde geral de Goldberg: manual técnico QSG - adaptação brasileira. São Paulo: Casa do Psicólogo.

Peterson, M., \& Wilson, J. F. (2002). The culture-work-health model and work stress. American Journal of Health Behavior, 26, 16-24.

Peiró, J. M. (1993). Desencadeantes del Estrés Laboral. Salamanca: Endema.

Porto, J. B., \& Tamayo, A. (2003). Escala de valores relativos ao trabalho: EVT. Psicologia: Teoria e Pesquisa, 19, 145-152.

Porto, J. B. (2004). Estrutura e transmissão dos valores laborais: um estudo com estudantes universitários. Tese de Doutorado, Universidade de Brasília, Brasília, DF.

Porto, J. B., \& Tamayo. A. (2008). Valores do trabalho. In M. M. M Siqueira, \& A. Tamayo (Eds.), Medidas do comportamento organizacional: ferramentas. Porto Alegre: Artmed. 
Proni, M. W. (2006). Duas teses sobre o trabalho no capitalismo. Ciência e Cultura, 58(4), 23-25.

Ribeiro, M. (2006). (In)Satisfação das prioridades axiológicas e saúde-doença mental no trabalho. Dissertação de Mestrado, Universidade Católica de Goiás, Goiânia.

Roccas, S., Sagiv. L., Schwartz, S., \& Knafo, A. (2002). The big five personality factors and personal values. Personality and Social Psychology Bulletin, 28, 789- 801.

Schwartz, S. H. (2005a). Validade e aplicabilidade da teoria de valores. In A. Tamayo \& J. B. Porto. (Eds.), Valores e comportamento nas organizações (pp. 56-95). Petrópolis, RJ: Vozes.

Schwartz, S. H. (2005b). Valores humanos básicos: seu contexto e estrutura intercultural. In A. Tamayo \& J. B. Porto. (Eds.), Valores e comportamento nas organizações (pp. 21-55). Petrópolis, RJ: Vozes.

Siu, O., Spector, P. E., Cooper, C. L., \& Lu, C. (2005). Work stress, self-efficacy, Chinese work values, and work well-being in Hong Kong and Beijing. International Journal of Stress Management, 12, 274-288.
Tamayo, A. (1988). Influência do sexo e da idade sobre o sistema de valores. Arquivos Brasileiros de Psicologia, 38, 91-104.

Tamayo, A. (2001). Prioridades axiológicas, atividade física e estresse ocupacional. Revista de Administração Contemporânea, 5, 127-147.

Tamayo, A. (2002). Exaustão emocional no trabalho. Revista de Administração, 37, 26-37.

Toledo, F., \& Regis, R. (1996). Recursos humanos e globalização. São Paulo: FTA.

Recebido em 17.06.2010

Primeira decisão editorial em 31.01.2012

Versão final em 02.11.2012

Aceito em 02.11.2012

\section{Psicologia e Envelhecimento}

Santos, SP, BR

19 de Fevereiro de 2013 